\title{
Bone density, osteoarthrosis of the hip, and fracture of the upper end of the femur
}

\author{
M. V. L. FOSS AND P. D. BYERS \\ Institute of Orthopaedics, London
}

Surgeons have often noticed the general absence of osteoarthrosis in the head of the femur excised in the treatment of fracture of the femoral neck. Ball (1966) confirmed this impression from his personal experience in the laboratory; this stimulated Byers, Contepomi, and Farkas (1970) to study such heads and to mention briefly that the progressive changes of osteoarthrosis were not seen in over 100 examined by them. These are the only available references to such findings.

It has often been noted that osteoporosis is commonly found in patients who suffer fracture of the upper end of the femur, and it has been suggested that osteoporosis is the major cause of such fractures (Alffram, 1964; Newton-John and Morgan, 1968; Chalmers and Ho, 1970). It was decided to attempt to confirm these two observations, and to extend the study to include patients with established osteoarthrosis of the hip, since there is no information in the literature about bone density in this disease.

\section{Material and method}

140 patients with upper femoral fractures, and 100 cases of osteoarthrosis of the hip have been studied. Of the 100 patients suffering from osteoarthrosis, 32 were male and 68 female. Of the 140 patients with fractures nineteen were male and 121 female. The average age of the fracture patients was 81 years (range 50 to 101) and of the patients with osteoarthrosis 63 years (range 50 to 83). Of the 78 patients with fractures internally fixed, the fractures were in the trochanteric region in 65 and subcapital in thirteen. Rheumatoid arthritis was excluded in all cases as far as possible.

An anteroposterior radiograph of the pelvis and hips of each of the fracture patients, taken shortly before operation, was studied. Evidence of osteoarthrosis was sought: superior or concentric joint space narrowing; sclerosis, cysts, or collapse of subchondral bone with irregularity of the subchondral bone plate and possible subluxation; subperiosteal new bone formation round the femoral neck; osteophytes, both central and marginal. The joint space as seen varies with the distance of the joint from the film, but a width of $2.5 \mathrm{~mm}$. was taken as the lower limit of normal in a concentric joint where other signs were absent. Eccentricity of the femoral head relative to the acetabulum was sometimes seen in displaced fractures, but the cartilage was regarded as being of normal thickness if concentricity was seen to have been restored in the radiograph taken after operation. Any radiological changes could of course be compared with the naked-eye appearance in cases in which the femoral head was excised. Radiographs of the hips of 100 osteoarthrosis patients were also studied and in all cases could be compared with a resected femoral head.

Sixty-two femoral heads removed in the treatment of fracture of the femoral neck, and two obtained post mortem from patients who had had internal fixation of a pertrochanteric fracture, and 100 femoral heads removed in the course of total hip replacement for osteoarthrosis have been studied. Articular cartilage changes were classified by the method of Byers and others (1970), who described fifteen features of the cartilage of the femoral head, apart from osteophytes, according to site and gross appearance. These formed two major groups:

(1) Alterations of limited progression,

(2) Progressive alterations.

The former were regarded as an age-related change, not associated with osteoarthrosis. The latter constituted the lesions of osteoarthrosis. The major features, in both area and frequency, of limited progression were below and behind the fovea, areas not in contact with the acetabular cartilage in the anatomical position. Five stages of development were recognized:

(1) Granularity;

(2) Fraying;

(3) Loss of cartilage;

(4) Ossification in the base of a Stage 3 alteration;

(5) Exposure of bone (found in five of 365 femoral heads in their series)

In all 240 patients an anteroposterior radiograph was taken of the right hand. Bone density was assessed from the measurements of the second metacarpal and expressed as a quotient by the formula of Exton-Smith, Millard, 
Payne, and Wheeler(1969). The results were plotted against age on their percentile charts derived from measurements taken from a normal population of 964 persons.

\section{Results}

Definite radiological evidence of osteoarthrosis was seen in only one of the 140 fractured hips. This patient had advanced Paget's disease and a pertrochanteric fracture of the femur; the femoral head was not available for examination. The radiographs of a second patient with a pertrochanteric fracture, on the same side as a hemiplegia of 3 years' duration, showed a normal superior joint space and two or three cysts in the subchondral bone: there were no other signs suggestive of osteoarthrosis. Such subchondral cysts can be seen underlying normal articular cartilage and by themselves do not indicate osteoarthrosis (Woods, 1961). Medial joint space narrowing alone was seen in the radiographs of eleven hips, and was taken to indicate the presence of limited change in the infrafoveal area, though of an advanced stage. This interpretation was substantiated in three of the four femoral heads with this sign that were excised: one had Stage 5 changes in this area, one Stage 4, and one Stage 3. The fourth femoral head came from a patient with generalized Paget's disease of the pelvis. There was medial joint space narrowing in the radiograph, but there was only a little sclerosis in the femoral head of the fractured side. The opposite hip showed fairly marked changes of osteoarthrosis. The excised femoral head showed a fairly large area of bone exposure round the fovea but normal cartilage elsewhere. Because of the association between Paget's disease and osteoarthrosis of the hip, the changes found in this case are being regarded as of osteoarthrosis: that is, progressive in character, even though located in an unusual site. The distinction between this and Stage 5 of the limited alterations has to be acknowledged as a fine point, and one in which we may be mistaken.

In the 64 femoral heads resected for fracture of the femoral neck, progressive cartilage changes were seen in two. One was from a 60-year-old female from a mental hospital, who had been walking on an im- pacted abduction fracture of the femoral neck for 2 months before falling again and displacing the fracture. The joint space appeared normal radiographically. The articular cartilage showed an early superficial lesion in the weight-bearing area of the femoral head which we feel must have occurred after the original fracture. The second case with progressive changes has been described above.

Limited changes were seen in all 64. These tended to be most advanced in the area below the fovea, that corresponding to the area of the acetabular fossa, and may be summarized as follows:

Completely normal articular cartilage surface

Stage 1 only: granularity of surface

Up to Stage 2: fraying

Up to Stage 3: loss of surface cartilage

Up to Stage 4: ossification of cartilage

Up to Stage 5: exposure of bone

Total

In this series of 140 patients with fractures of the upper end of the femur, only three are regarded as having osteoarthrosis of the affected hip. Two patients suffered from Paget's disease and in the third there is doubt about the presence of osteoarthrosis at the time of fracture. One might be justified in eliminating these three patients from a study of the prevalence of osteoarthrosis in the hip at the time of fracture in uncomplicated cases. One can say, therefore, that osteoarthrosis of hip with a recently fractured upper end of the femur is unlikely to be found.

Of the 100 femoral heads resected in the course of total hip replacement for osteoarthrosis, all showed severe progressive changes-cartilage loss in that part of the femoral head corresponding, in the anatomical position, to the horseshoe-shaped acetabular joint surface. Many showed more extensive destruction and bone collapse.

The distribution of all cases in this study relative to age, bone density, and the normal percentile curves for bone density is shown in Fig. 1 (males) and Fig. 2 (females). It will be seen that there is a marked preponderance of fracture cases at the $O$ osteoporotic end of the scale (Table I).

Table I Analysis of fracture cases relative to normal bone density percentiles

\begin{tabular}{|c|c|c|c|c|c|c|}
\hline \multirow[t]{3}{*}{ Fracture } & & \multirow{3}{*}{$\begin{array}{l}\text { Per cent. } \\
\text { of total }\end{array}$} & \multicolumn{4}{|l|}{ Sex } \\
\hline & & & \multicolumn{2}{|c|}{ Male } & \multicolumn{2}{|c|}{ Female } \\
\hline & & & No. & Per cent. & No. & Per cent. \\
\hline $\begin{array}{l}\text { Above } \\
\text { Below }\end{array}$ & $\begin{array}{l}\text { 90th percentile } \\
\text { 50th percentile } \\
\text { 50th percentile } \\
\text { 10th percentile }\end{array}$ & $\begin{array}{l}1 \cdot 5 \\
24 \cdot 3 \\
75 \cdot 7 \\
45\end{array}$ & $\begin{array}{r}0 \\
5 \\
14 \\
12\end{array}$ & $\begin{array}{l}0 \\
26 \cdot 3 \\
73 \cdot 7 \\
63\end{array}$ & $\begin{array}{r}2 \\
29 \\
92 \\
51\end{array}$ & $\begin{array}{l}1 \cdot 7 \\
24 \\
76 \\
42\end{array}$ \\
\hline \multicolumn{2}{|c|}{ Totals in series } & 140 & 19 & & 121 & \\
\hline
\end{tabular}




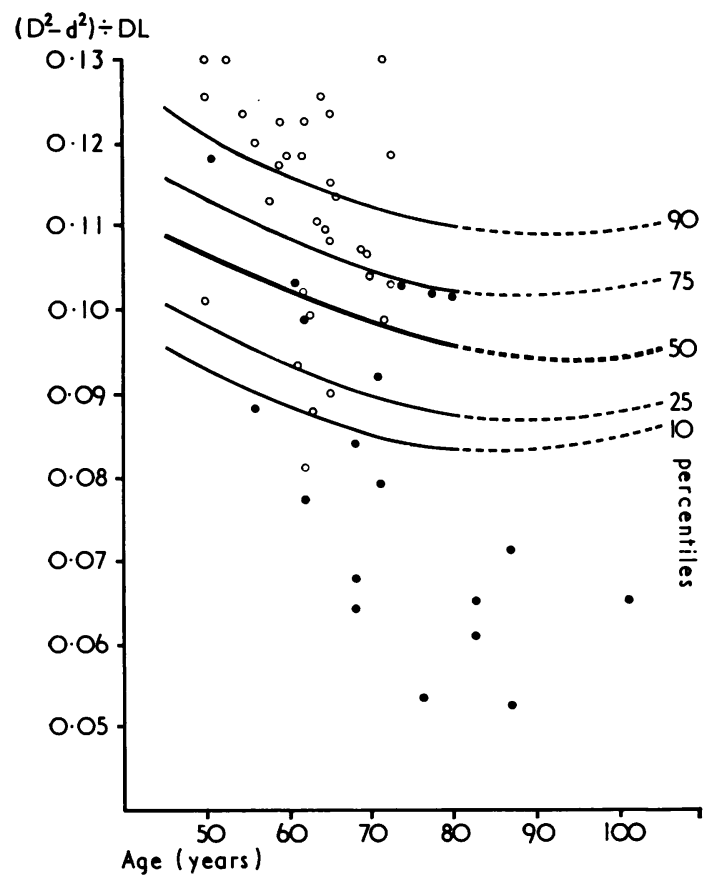

FIG. 1 Distribution of male patients by bone density and age, relative to normal bone density percentile lines. Open circles-cases with osteoarthrosis. Closed circlesfractures of femoral neck.

There is a reasonable similarity of distribution between males and females, and they are combined in Fig. 3.

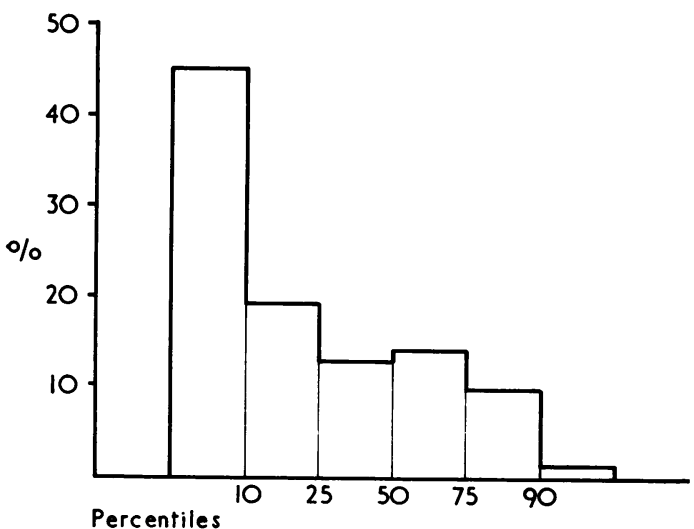

FIG. 3 Percentage distribution of fracture cases by bone density percentile groups.

Figures 1 and 2 show that a large proportion of osteoarthrosis cases are high on the bone density scale (Table II, overleaf).

Again there is reasonable similarity of distribution between males and females, and they are combined in Fig. 4.

The striking result of this study is the finding of an

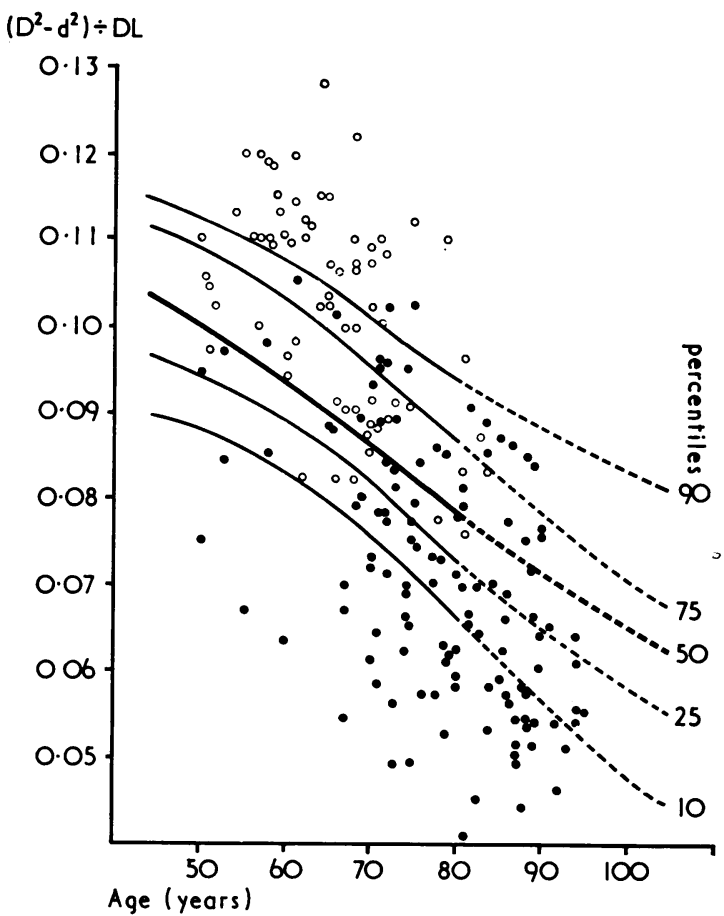

FIG. 2 Distribution of female patients by bone density and age, relative to normal bone density percentile lines. Open circles-cases with osteoarthrosis. Closed circlesfractures of femoral neck.

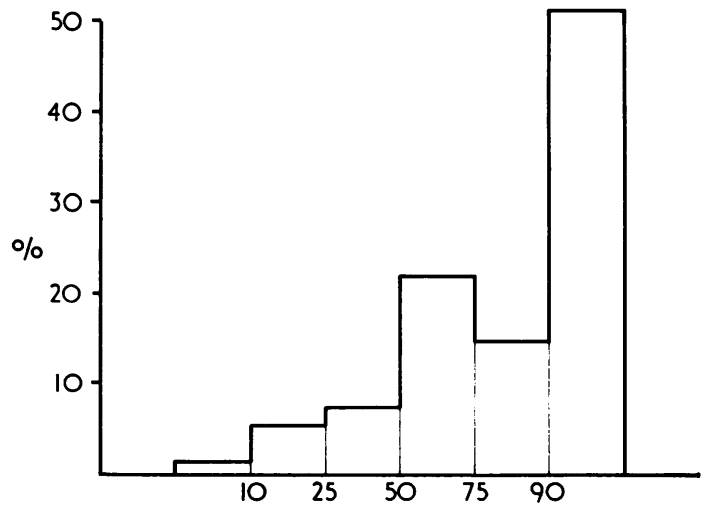

Percentiles

FIG. 4 Percentage distribution of osteoarthrosis cases by bone density percentile groups.

abnormally high bone density in the majority of patients with osteoarthrosis. Taking a purely arbitrary decision to place the limits of normal bone density at the 10th and 90th percentiles, the 240 patients in this study can be divided into three groups:

(a) Those with an abnormally high bone density and osteoarthrosis of the hip (51);

(b) Those with osteoporosis and fracture of the upper end of the femur (63); 
Table II Analysis of osteoarthrosis cases relative to normal bone density percentiles

\begin{tabular}{|c|c|c|c|c|c|c|}
\hline \multicolumn{2}{|c|}{ Osteoarthrosis } & \multirow{3}{*}{$\begin{array}{l}\text { Per cent. } \\
\text { of total }\end{array}$} & \multicolumn{4}{|c|}{ Sex } \\
\hline & & & \multicolumn{2}{|c|}{ Male } & \multicolumn{2}{|c|}{ Female } \\
\hline & & & No. & Per cent. & No. & Per cent. \\
\hline $\begin{array}{l}\text { Above } \\
\text { Below }\end{array}$ & $\begin{array}{l}\text { 90th percentile } \\
50 \text { th percentile } \\
\text { 50th percentile } \\
\text { 10th percentile }\end{array}$ & $\begin{array}{r}51 \\
87 \\
13 \\
1\end{array}$ & $\begin{array}{r}15 \\
26 \\
6 \\
1\end{array}$ & \begin{tabular}{r|}
47 \\
$81 \cdot 3$ \\
$18 \cdot 7$ \\
$3 \cdot 1$
\end{tabular} & $\begin{array}{r}36 \\
61 \\
7 \\
0\end{array}$ & $\begin{array}{l}53 \\
89 \cdot 7 \\
10.3 \\
0\end{array}$ \\
\hline \multicolumn{2}{|c|}{ Totals in series } & 100 & 32 & & 68 & \\
\hline
\end{tabular}

(c) Those with normal bone density and either osteoarthrosis of the hip or fracture of the upper end of the femur (126).

\section{Discussion}

Quite apart from certain specific (for instance, endocrine) causes of osteoporosis, it is generally agreed that loss of bone normally accompanies ageing (Newton-John and Morgan, 1968; Nordin, Barnett, Smith, and Anderson, 1966; Harris and Heaney, 1969). Adams, Davies, and Sweetnam (1970), in a longitudinal study, showed that most of their patients lost bone steadily during an 11-year period. Osteoporosis seems to be more common in the elderly institutionalized individual lacking physical activity (Engh, Bollet, Hardin, and Parson, 1968). Osteoporosis is more common in women (Harris and Heaney, 1969), and women with symptomatic osteoporosis have been found to be significantly lighter in weight than the normal for their age (Saville and Nilsson, 1966). Garn, Rohmann, Pao, and Hull (1966) state that women, with a smaller bone mass to begin with, lose bone faster than men to the point where mechanical integrity may be impaired. Newton-John and Morgan (1968) agree, saying that patients with thin bones are more susceptible to fracture.

The incidence of fracture of the upper end of the femur almost parallels that of osteoporosis (NewtonJohn and Morgan, 1968) and has been used as a criterion for the diagnosis of osteoporosis (Chalmers and Ho, 1970). Low body weight (and lesser bone mass) has been a feature found more commonly in a series of women with femoral neck fractures than in two control series (Alffram, 1964). There is some evidence that those who spend their lives in physical toil are less likely to develop osteoporosis (Dent, Engelbrecht, and Godfrey, 1968) and may suffer fractures of the upper end of the femur less frequently than those in more civilized communities (Levine, Makin, Menczel, Robin, Naor, and Steinberg, 1970; Chalmers and Ho, 1970). Stevens, Freeman, Nordin, and Barnett, (1962) stated that osteoporosis may be found in over 80 per cent of females over 60 years of age who suffer fracture of the upper end of the femur. Dequeker (1970), using the metacarpal measurements of Exton-Smith and others (1969), found that 31 per cent of 55 patients with fractures of the femur, humerus, and radius were below the 10th percentile for bone density. The $\mathbf{4 5}$ per cent found in the present series is more in agreement with the latter figure.

Osteoarthrosis of the hip is a relatively common disease. Kellgren and Lawrence (1958) stated that the incidence of all grades may be as high as 20 per cent in persons over the age of 55 years. Danielsson (1966), examining the radiographs of the hips of 3,903 patients having Barium enemas, found an incidence of Grade II (C.I.O.M.S., 1963) or worse osteoarthrosis in 3.4 per cent of patients over the age of 55 years. Byers and others (1970), examining 365 post mortem hips, found a 3.2 per cent incidence of progressive changes in the articular cartilage in the over-60 age group. Kellgren's Grade I radiographic change (C.I.O.M.S., 1963) is probably indicative only of limited articular cartilage changes. Osteoarthrosis of the hip is normally secondary to some stress-producing mechanical defect of the femoral head or acetabulum, such as a slipped capital epiphysis or dysplasia (Kellgren and Lawrence, 1958; Murray, 1965), and the 'tilt deformity' has been shown by Murray and Duncan (1971) to be commoner in athletic boys. Their conclusion is that these active individuals may be more likely to go on to develop osteoarthrosis than their less active contemporaries. There is also a preponderance of obesity in those suffering from osteoarthrosis of the hip (Kellgren and Lawrence, 1958).

Increased stress at the hip results in local bone accretion particularly under the calcar femorale, but it is also postulated that a high level of physical activity increases bone density generally. In addition to the evidence which points to exercise as a cause of osteoarthrosis by direct damage to joint architecture or articular cartilage (Murray, 1965; Murray and Duncan, 1971), there is some evidence to suggest that osteoarthrosis may be caused by loss of resilience of subchondral bone (Radin and Paul, 1970). If this 
is so, and if an increase in bone density is associated with a loss of resilience, then physical activity may have a two-fold effect in the causation of oesteoarthrosis. The converse, of course, might also apply: if osteoporotic bone is more resilient, then it might be expected to cushion and protect articular cartilage, and this might explain the rarity of osteoarthrosis of the hip in osteoporotic patients.

All this evidence seems to present a picture of older people as a spectrum. At one end is the light, small-boned osteoporotic female (without osteoarthrosis of the hip) who takes little exercise and who suffers a fracture of the upper end of the femur. At the other end is the well-built individual, probably active all his life, who has strong bones but suffers from osteoarthrosis of the hip. However, this is but a representation of the latter part of the story: it seems likely that the stage is set while the bone is developing in size, and while bone density is increasing up to the age of 30 or 40 years (Exton-Smith and others, 1969). There is good correlation between the bone density percentile curves and weight-for-age percentile curves in children (Gryfe, Exton-Smith, Payne, and Wheeler, 1971), and it would seem that those who start life on a low percentile ranking might, in the normal course of bone resorption in old age, go on to osteoporosis.

It may be that general bone density can be increased in youth by physical labour and exercise, and that this could explain the relative lack of osteoporosis and upper femoral fractures in less civilized populations, where weight and height percentile rankings in children are probably low in consequence of poor nutrition. Physical activity (including the stress of obesity) or lack of it after bone development has ceased may well affect bone density and articular cartilage (Kellgren and Lawrence, 1952; Lawrence, 1955). While most people's bone density quotient remains parallel to the mean over the years, this is not universal (Adams and others, 1970). In some people bone density may increase relative to the mean and in some it certainly decreases. It is of course possible that bone density, increased in youth by vigorous activity, may revert to normal with lack of exercise in later life. It may even decrease to the level of osteoporosis, though this seems less likely in view of the rare coincidence of osteoporosis and osteoarthrosis. Again it is possible that increased bone density is a result and not a cause of osteoarthrosis of the hip. It is proposed that a longitudinal study of patients with early osteoarthrosis of the hip shall be made. We would expect bone density in these patients to follow percentile lines or perhaps decrease relative to percentile lines, with time and the progress of their disease, as we contend that these patients must reach their bone density peak before osteoarthrosis becomes manifest.

\section{Conclusion}

The findings from this study indicate that osteoarthrosis is associated with above average bone density, and that osteoporosis and osteoarthrosis of the hip do not normally occur together. It is possible, in the light of existing ideas, to explore relationships between bone density and osteoarthrosis and to suggest that the degree of physical activity at different times during the life of an individual has an important function in the aetiology of both osteoarthrosis and osteoporosis.

\section{Summary}

This study shows that most patients who suffer from osteoarthrosis of the hip joint have a (metacarpal) bone density that is greater than normal for their age. It confirms the association between fracture of the upper end of the femur and osteoporosis and shows that osteoarthrosis of the hip is hardly ever found in such patients. The implication of these findings in relation to the cause of these conditions is discussed.

The authors are most grateful to the Orthopaedic Surgeons at the Royal National Orthopaedic Hospital, the Whittington, Barnet, Edgware and Watford Hospitals, for the use of clinical material from their patients; to Mrs. B. Glennie and Miss P. Ruskin for their assistance and to the Arthritis and Rheumatism Council for financial support.

\section{References}

Adams, P., Davies, G. T., And Sweetnam, P. (1970) Quart. J. Med., 39, 601 (Osteoporosis and the effects of ageing on bone mass in elderly men and women)

AlfFram, P.-A. (1964) Acta orthop. scand., Suppl. 65 (An epidemiologic study of cervical and trochanteric fractures of the femur in an urban population)

BaLL, J. (1966) Personal communication

Byers, P. D., Contepomi, C. A., AND Farkas, T. A. (1970) Ann. rheum. Dis. 29, 15 (A post mortem study of the hip joint)

Chalmers, J., AND Ho, K. C. (1970) J. Bone Jt Surg., 52B, 667 (Geographical variations in senile osteoporosis)

C.I.O.M.S. SYMPosium, ed. J. H. Kellgren (1963) 'Epidemiology of Chronic Rheumatism', Vol. 2, 'Atlas of Standard Radiographs of Arthritis', p. 12. Blackwell, Oxford

Danielsson, L. (1966) Clin. Orthop., no. 45, p. 67 (Incidence of osteoarthritis of the hip (coxarthrosis)) 
DeNT, C. E., ENGLebrecht, H. E., AND GodfRey, R. C. (1968) Brit. med. J., 4, 76 (Osteoporosis of lumbar vertebrae and calcification of abdominal aorta in women living in Durban)

DequekeR, J. V. (1970) Lancet, 1, 359 (Pattern of development and loss of bone with age)

Engh, G., Bollet, A. J., Hardin, G., AND Parson, W. (1968) J. Bone Jt Surg., 50A, 557 (Epidemiology of osteoporosis)

Exton-Smith, A. N., Millard, P. H., Payne, P. R., AND Wheeler, E. F. (1969) Lancet, 2, 1154 (Pattern of development and loss of bone with age)

Garn, S. M., Rohmann, C. G., PaO, E. M., and Hull, E. L. (1966) 'Normal osteoporotic bone loss', in 'Progress in Development of Methods in Bone Densitometry', ed. G. D. Whedon, W. F. Neumann, and D. W. Jenkins, p. 187. National Aeronautics and Space Administration, Washington

Gryfe, C. I., Exton-Smith, A. N., PAyne, P. R., AND Wheeler, E. F. (1971) Lancet, 1, 532 (Pattern of development of bone in childhood and adolescence)

HarRis, W. H., aNd Heaney, R. P. (1969) 'Skeletal Renewal and Metabolic Bone Disease'. Little, Brown, Boston.

KellgRen, J. H., AND LAWRENCE, J. S. (1952) Brit. J. industr. Med., 9, 197 (Rheumatism in miners: $X$-ray study)

- AND LAWRENCE, J. S. (1958) Ann. rheum. Dis. 17, 388 (Osteoarthrosis and disc degeneration in an urban population)

LAWRENCE, J. S. (1955) Brit. J. industr. Med., 12, 249 (Rheumatism in coal miners: occupational factors)

Levine, S., Makin, M., Menczel, J., Robin, G., NAOR, E., AND Steingerg, L, (1970) J. Bone Jt Surg., 52A, 1193 (Incidence of fractures of the proximal end of the femur in Jerusalem)

MURRAY, R. O. (1965) Brit. J. Radiol., 38, 810 (The aetiology of primary osteoarthritis of the hip)

- AND DunCAN, C. (1971) J. Bone Jt Surg., 53B, 406 (Athletic activity in adolescence as an etiological factor in degenerative hip disease)

Newton-John, H. F., AND MoRGan, D. B. (1968) Lancet, 1, 232 (Osteoporosis: disease or senescence?)

Nordin, B. E. C., BARNETT, E., SMITH, D. A. AND ANDERSON, J. (1966) 'Measurement of cortical bone volume and lumbar spine density', in 'Progress in Development of Methods in Bone Densitometry', ed. G. D. Whedon, W. F. Neumann, and D. W. Kenkins, p. 21. National Aeronautics and Space Administration, Washington

RADIN, E. L., AND PAUL, I. L. (1970) Arthr. and Rheum., 13, 139 (Does cartilage compliance reduce skeletal impact loads?)

Saville, P. D., AND Nilsson, B. E. R. (1966) Clin. Orthop., no. 45, p. 49 (Height and weight in symptomatic postmenopausal osteoporosis)

Stevens, J., Freeman, P. A., NoRdin, B. E. C., AND BARNETt, E. (1962) J. Bone Jt Surg., 44B, 520 (Incidence of osteroporosis in patients with femoral neck fractures)

Woods, C. G. (1961) Ibid., 43B, 758 (Subchondral bone cysts) 